\title{
The Study of Corrosion Behaviour of Intumescent Fire Retardant Coating with Structural Steel Substrate
}

\author{
W. C. Puspitasari ${ }^{1}$, Faiz Ahmad ${ }^{1, *}$, Sami Ullah ${ }^{2}$, M. Rafi Raza ${ }^{3}$, P. Hussain ${ }^{1}$, P.S.M. Yusoff ${ }^{1}$ and \\ Yasmin, Azmi ${ }^{1}$ \\ ${ }^{1}$ Mechanical Engineering Department, Universiti Teknologi PETRONAS Bandar Seri Iskandar, \\ 32610, Perak, Malaysia. \\ ${ }^{2}$ Department of Mechanical Engineering, University of Gujrat, 50700, Pakistan. \\ ${ }^{3}$ Department of Mechanical Engineering, COMSATS Institute of Information Technology, Sahiwal \\ 57000, Pakistan \\ *E-mail: faizahmadster@gmail.com
}

doi: $10.20964 / 2018.10 .30$

Received: 28 January 2018/ Accepted: 9 May 2018 / Published: 1 September 2018

\begin{abstract}
The aim of this work is to study corrosion behaviour of intumescent coating and the primer on steel substrate before and after a fire test. The coated steel substrates were subjected to fire in a furnace at $950^{\circ} \mathrm{C}$ for a variable duration ranging from 30, 45, 90 and $120 \mathrm{~min}$. All coated steel substrates were also subjected to corrosion test by immersing them in $5 \% \mathrm{NaCl}$ solution, for $15 \mathrm{~min}$ and three months duration using Electrochemical Impedance Spectroscopy (EIS). The specimen's impedance before fire test and before immersion was $4.37 \times 10^{8} \Omega . \mathrm{cm}^{2}$. After $15 \mathrm{~min}$ exposure to $\mathrm{NaCl}$, this value was reduced by $26,53,60$ and $65 \%$ for specimens fired for 30, 45, 90 and $120 \mathrm{~min}$, respectively. Further reduction in the impedance by $97.6,97.8,97.9$ and $98.9 \%$ for samples fired for 30, 45, 90 and $120 \mathrm{~min}$, respectively, were measured after three months in $5 \% \mathrm{NaCl}$ immersion.
\end{abstract}

Keywords: Intumescent fire retardant coating; Corrosion; Electrochemical Impedance Spectroscopy (EIS); Fire test; Salt spray

\section{FULL TEXT}

(C) 2018 The Authors. Published by ESG (www.electrochemsci.org). This article is an open access article distributed under the terms and conditions of the Creative Commons Attribution license (http://creativecommons.org/licenses/by/4.0/). 